\title{
From Sound to Sound Space, Sound Environment, Soundscape, Sound Milieu or Ambiance...
}

\section{MAKIS SOLOMOS}

\section{Sound and Relationality}

What is a sound?

Imagine spending a spring Sunday in the countryside. You walk aimlessly, lost in the plurality of your thoughts and sensations. You become gradually aware of a plane in the sky, but you don't know when it appeared and will probably not have the patience to listen to it until it disappears completely. A soundscape is progressively emerging from this plane-sound: the croaking of nearby crows emerges, the chainsaw in the distance begins to take on a new meaning and even the rustle of the wind in the trees becomes part of this rich fusion of sounds. But your mood, too, is affected - if you are sensitive to the sensation of the sublime, you will be fascinated by this long sound trail in such a vast open space. It makes you listen to the interweaving sounds differently, as well as making you aware of the way they are anchored in the environment and of your own relationship to the earth and the sky. Sound defines itself as a network of relationships: to other sounds, to the ambient space and to the subject who listens. It would be more precise to talk about 'sound milieus' than about sound.

Let us bypass the phenomenological description and turn to the physicalist one. A basic definition tells us that sound is made up of a pressure wave created by a vibrating object. The vibration is transmitted by the molecules of the milieu in which the sound spreads. It is customary to add that sound is also the auditory sensation brought forth by this vibration. An object in vibration moves in a milieu and

Paragraph 41.1 (2018): 95-109

DOI: $10.3366 /$ para.2018.0253

(C) Edinburgh University Press

www.euppublishing.com/para 
transforms into a sensation of hearing: sound does indeed manifest itself through a network of relationships.

Is sound an object? This question grew out of the birth of recording: sound, whether it is captured or rendered identically on to a disc, magnetic band or computer hard drive, appears to be physically there in front of us. Acoustic sound does not reveal itself in the same manner. It is always the sound of something: of a door, of a plane, of a voice... It is contingent upon the event and cannot be duplicated; it exists only as a function of the time and place of its creation. It is inextricably linked to its environment and to the cause that produced it.

Recording, being more rigid that the writing of words, swaps these priorities: the sound becomes primary, the gesture tends to disappear and the cause of the sound is relegated to the background. Recording seeks to freeze the sound, or at least to 'fix' it (to a medium), as practitioners of musique concrète like to say, or to reify it: it is as if sound becomes an object. Pierre Schaeffer, the inventor of musique concrète, liked to say that it was due to the 'accident of the closed groove' that this became possible: a closing groove, in its endless repetition of a sound, transforms it into a sound object. ${ }^{1}$ In order to produce a sound object, Schaeffer makes the case for 'reduced listening,' in which one attempts to forget the origin of the sound and hear only the sound 'in itself'.2

The idea of a sound object enables us to immerse ourselves in the intimacy of sound. It is this that leads Schaeffer to analyse 'sound morphology', in which sound is treated according to its own characteristics: mass, dynamic, timbre and so forth. ${ }^{3}$ This process of musicalizing sound allows us to apprehend the pleasure of the matter, forms and temporal progression of the universe of sound. Such a process, however, is hardly natural, and goes against our relationship to the world. For in reality the act of listening tends to contextualize sound. It looks for a cause and an origin, even with recorded sound. The listener always considers the sound played through loudspeakers as the sound-of (something) and searches for its origin or invents one. At the same time, he interprets this sound in relation to the space in which it is played, as well as to the speakers that emit it; the speakers then become the source of the sound. In a similar vein, isolating a sound, or abstracting it from the encompassing sonic fabric in order to create a separate entity, is also artificial: it seems arbitrary to isolate a sound in time as in space or in the larval flow of perception. 
More than an object, sound is an event. Several authors have noted this characteristic. Michel Chion tells us that sound is 'predominantly event-driven', as it stretches out in time:

It's the paradox of what Schaeffer called the 'closed groove', these small seconds of sound (...) An object has indeed been captured, but it is like a bird that does not stop fluttering around its cage, whose movements cannot be restrained in order for it to be observed. Even in its recorded form (...) sound continues to move, because otherwise there would no longer be any sound. ${ }^{4}$

Time is consubstantial with sound. Sound is not 'in' time; rather time is invented as a sound spreads out. Roberto Casati and Jérôme Dokic also defend this event-based conception. Referring to event theory, they take an original approach by adhering to the event-based notion of sound and underlining its spatiality: 'One of the principal theses of this book is that the understanding of the events-driven quality of sounds is crucial in order to establish a correct theory about the spatial characteristic of the auditory perception.' 5 Finally, I will cite the composer Agostino Di Scipio, who shares this concern about the critique of sound, which precisely begins with the critique of sound conceived as an object:

Never truly an object, sound is thus always an event. In its passage across time, in its three-dimensional propagation, sound spreads around and within the body that listens to it, while at the same time extending through the body of the source. When it takes places (and this takes time), sound also takes on the semantic connotations of the space: it is an event in the environment and of the environment. ${ }^{6}$

Sound also constitutes a form of energy, with regards to the energy produced by acoustic waves. This form of energy impacts the listener in his entirety, as well as the environment. The art of sounds, or music, has frequently been considered a sort of energy, particularly in modern music. Philippe Leroux mentions the 'traces of energy left by gestures' and 'energy phrases', 7 while François Bayle develops the idea of an 'energy logic'. ${ }^{8}$ Gérard Grisey defines timbre as 'a correlated collection of energies'. The term can even be traced back to Varèse. ${ }^{10}$

Xenakis is the definitive composer who treats music as an energy phenomenon. ${ }^{11}$ 'A musical work is a collection of energetic transformations', he wrote in his unpublished drafts for Concret PH (1958), a musique concrete piece based on the crackling of burning embers. ${ }^{12}$ It was during this time that he developed the sound theory 
that would later be called 'granular', in which a sound is created from a large number of very short impulses, below the threshold at which one can perceive the length of a sound. These are called 'grains', or sound 'quantas'. 13

The granular theory of sound, which also dates back to the physicist Dennis Gabor, is an alternative paradigm of the vibratory model. As we have seen, both share the concept of energy, but the granular theory decisively offers two other characteristics of sound: complexity and emergence, qualities that go hand in hand. In granular theory, sound structures can be thought of as 'dissipation sonic energy structures', according to Horacio Vaggione, ${ }^{14}$ who drew inspiration from Ilya Prigogine's works and from complex systems. When it comes to the element of emergence, for granular theory 'sound' is not a given in and of itself. Sound grains are not sounds, but acoustic signals too short to be perceived as sounds (the human ear perceives sounds shorter than one-twentieth of a second as clicks). There is sound when the grains are assembled in a way that is meaningful to the ear, which then perceives them as a whole and, in a sense, synthesizes them. Thus it is that sound appears according to the logic of emergence, as part of an evolution that generates new properties as it reaches a critical threshold of complexity.

Another set of characteristics of sound may be described with adjectives such as synthetic and encompassing, inclusive and immersive, present and full. The list goes on. Synthetic is the primary characteristic of hearing, as opposed to sight, which is analytic. Sound and sound structures are presented as global events, forming gestalts, or coherent structures. Hearing detects a 'melody' from the succession of suitable notes, not just a mass of notes. Similarly, during a sonic event, one may hear a 'single' sound even though one could be in fact hearing bursts of sounds - and I am not talking here about granular sounds.

Music which is oriented towards sound - that is, which is focused on sound itself rather than more abstract structures ${ }^{15}$ - is often immersive, a characteristic strengthened by the fact that hearing is omnidirectional. Here one might speak of an 'inner life' of sound, the pleasure of being in the sound, of immersing oneself in it, of enfolding oneself in it. The most extreme cases give rise to a kind of mysticism of sound as in Giacinto Scelsi, who sought out the 'third dimension' of sound, its 'depth': 'Sound is spherical, but upon hearing it, it appears to have just two dimensions, pitch and duration. We know that depth, the third dimension, exists, but in a certain way it escapes us., ${ }^{16}$

We can also consider sound's capacity for presence with regards to the space in which sound is born, unfurls, transforms and dies, in, 
by and with time. In sound music, this tendency towards presence is strengthened because the music is so much harder to remember or anticipate. Just as it is easy, with a melody, to remember the first note and anticipate those that follow, it is challenging to memorize sonic forms and anticipate their evolution precisely because of their complexity. Sound, in relation to its presence, additionally confers a feeling of plenitude. This characteristic undoubtedly comes from the fact that we listen with our entire body: it cannot be denied that sound has a haptic dimension. This dimension can be quite literal, if we consider sound in terms of vibration; it can be overwhelming in the case of very low sounds that can trigger serious discomfort. Otherwise, this aspect of sound is simply suggested, in a vast zone that stretches from touch to affect.

The characteristics that have been described above lead to an understanding of sound as something other than an object; the idea of defining sound, whether through artistic experimentation or conceptualization, as a network of relationships begins to take shape. Other characteristics can be attributed to it as well. Roberto Barbanti alludes to the 'ontological coexistence' of sound and listener and 'nonseparation':

The notion of ontological 'coexistence' recalls a certain immanence and a sense of belonging to the world, a common vibration that makes my being attuned to the shifting energies of other beings, other objects and natural elements that are vibrating here and now. (...) While sight is the only sense that requires the object in question to distance itself in order to function and reveal its essence, hearing immediately raises the issue of 'non-separation'. ${ }^{17}$

Sound is what connects us to our environment, both auditory and non-auditory, and to the world. We inhabit sound, just as we inhabit the earth: ${ }^{18}$ our brain is not an information processing system and sound is not the object of this processing. We must therefore continue our attempts to conceptualize and search for new concepts that will allow us to consider the inextricable links between the vibrating object, the milieu in which the vibration spreads and the subject who listens.

\section{Sound Space, Sound Environment, Soundscape, Sound Milieu,} Sound Ambiances

The use of compound expressions, such as sound spaces, sound environments, soundscapes, sound milieus or sound ambiances, instead of the single word 'sound', has become more and more common. These expressions seek specifically to take into account situations in 
which sound is not understood as an object but defined in the context of a network of relationships.

The notion of sound space has been widely used in music, beginning with new music. For contemporary musicians and sound artists, space now appears as a necessary extension of sound. This inextricable link between sound and its propagation (as well as its composition) in space is exemplified by the notion of 'space-sound' works. ${ }^{19}$ The expression 'sound space' has recently gained new ground, stretching from sound studies to environmental ecology studies and encompassing music, theatre and other performance arts, as well as geography, urbanism and architecture, design, ethnology, sociology and so forth. ${ }^{20}$ Yet the concept remains ambiguous and seems to be used as a default; moreover, though its scope is interdisciplinary, it frequently drifts away from strictly sound-related issues.

The notion of a sound environment is undoubtedly used much more frequently. It too is often used as by default to designate 'that which surrounds'. It designates the entirety of sounds that encircle us, sounds that are not organized into a hierarchy, as is the case with a 'soundscape'. ${ }^{21}$ As a result, this notion indicates an objective reality or raw data that does not interact with the individual and his listening. It is for this reason that it is less interesting than the three other notions that we will now explore.

The notion of soundscape seems to be rooted not only in the vocabulary of the humanities, fine art and sound studies, but also in all the disciplines previously mentioned that gravitate towards sonic space and take environmental issues into consideration. Barry Truax defined it as 'an environment of sound (or sonic environment) with emphasis on the way it is perceived and understood by the individual or by a society. It thus depends on the relationship between the individual and any such environment.'22

Murray Schafer is frequently cited as having invented the word in a booklet intended for teaching music: 'I had derived it from the word "landscape", which was equally unknown until Petrarch, the fourteenth-century Italian poet and scholar, decided one day to walk to the top of a mountain in order to see the view. What he saw was something that had never been seen before and therefore had to be described by a new word: Landscape. ${ }^{23}$ In his famous work The Tuning of the World (1977), Schafer defines the concept of soundscape as establishing the link between man and his environment. His concerns are ecological: a large portion of the book is devoted to the issue of sound pollution. In order to study the idea of soundscape - and fight 
sound pollution - Schafer calls for an interdisciplinary reading and adds that 'the home territory of soundscape studies will be the middle ground between science, society and the arts'. ${ }^{24}$

Art is called upon to play a large role and one of the book's four sections is devoted to acoustic design:

The best way to comprehend what I mean by acoustic design is to regard the soundscape of the world as a huge musical composition, unfolding around us ceaselessly. We are simultaneously its audience, its performers and its composers. Which sounds do we want to preserve, encourage, multiply? (...) Acoustic design is not merely a matter for acoustic engineers. Acoustic design should never become design control from above. It is rather a matter of the retrieval of a significant aural culture, and that is a task for everyone. ${ }^{25}$

In making the case for the world as a musical composition, Schafer and his followers reveal a certain mysticism, or Pythagoreanism. But what is of particular interest is that Schafer remains a musician, albeit a musician who seeks to break with the idealism that continues to dominate music: 'Composers are not yet ready to assume the leadership role in reorchestrating the world environment. Some are still devoting themselves with waspish bitterness to a Parnassus of two or three. ${ }^{\text {,2 }}$

Listening is the common thread between music and the other disciplines required to study the concept of soundscapes (and to fight against sonic pollution); it is a matter of restoring the importance of an auditory culture, as much for musicians who listen deeply to their music but are deaf to the world, as it is for non-musicians who have not learned to listen. This focus on listening is the common ground linking Murray Schafer and Pierre Schaeffer, whose Traité des objets musicaux is in many respects a treatise on listening. Schafer, for his part, pays homage to Schaeffer's efforts to conceptualize a sonic morphology while still critiquing him for isolating sounds and cutting them off from their environment and their cause. The Traité des objets musicaux and The Tuning of the World can be considered as the two major post-1945 theoretical efforts to discuss and analyse sound, or, in other terms, to recognize the important role that sound has assumed. The two can be treated as complementary (or the second as contradicting the first): while Schaeffer summons us to listen to the sound object, or the sound in and of itself, Schafer invites us to discover the relationship between a sound and its environment, that is, to theorise soundscape.

Now that we have outlined the principal elements of the concept of soundscape, as developed by acoustic ecologists, we must ask whether this concept is (still) useful. As we have seen, its principal merit is 


\section{Paragraph}

its consideration of sound in terms of relationships, on the one hand rejecting its being defined as an object, or refusing to isolate the sound from its environment, and, on the other hand, taking into account the auditory perspective of the listener. The expression is thus aligned with our attempts to identify the interactions between the vibrating object, the milieu in which it vibrates and the listener who feels the vibration. Many critics, however, have been vocal in their opposition.

In an article titled 'Against Soundscape', Tim Ingold assuredly emerges as the loudest critic. ${ }^{27}$ He posits, among other arguments, that the world we experience is not divided along the lines of the various senses. For Ingold, there is only a single comprehensive 'landscape', and no soundscape in the same way as there is no purely visual or olfactory -scape. A landscape becomes visual only when it is painted; it is sonic only when it is recorded. Ingold, comparing sound to light (rather than to a visible object or an image), argues that just as visual studies tend to subordinate the sense of sight to the image, thus viewing eyes as instruments that reproduce images rather than as perceptive organs, there is a significant risk that soundscape studies reduce ears to being simply playback instruments.

This latter point is worth developing. The notion of soundscape indeed implies a totality, a coherent and organized entity. There are numerous sonic layers in a soundscape (they may be situated closer, farther, higher, lower), precise locations for each sound and an overall cohesion. Yet as sound evolves in time, this global approach does not line up with the hearing process, with sound as it is heard; it works only for captured sound, or recorded sound, because this is sound that has been 'fixed' in a medium and can be reproduced. The same problem applies to the (visual) landscape, though to a lesser degree; sight is similarly capable of taking in the landscape in its entirety.

In reality, the most important issue regarding the concept of soundscape is that it remains modelled on the visual: the organized entirety that it produces assumes a global view, precisely. In other words, while the concept of sight is largely exemplified by a man contemplating an array of elements from a mountaintop, its direct equivalent in the sphere of listening exists but is rather overshadowed by another model: that of a man immersed in the sonic whirlwind of a city, of a waterfall or even of a silent desert. As a result of all the characteristics of sound and listening that we have discussed, they call for immersion rather than contemplation. There are indeed soundscapes, but other expressions must also be found in order to qualify the relational experience brought about by sound spaces. 
Sound milieus may well serve this purpose. The expression is still uncommon, but it has started to appear in geography, in sound studies, in sonic design and in ethnomusicology... It remains a generic term, synonymous with space, environment or sonic ambiance. ${ }^{28} \mathrm{~A}$ small digression into the notion of milieu, as developed by Jakob von Uexküll and Gilbert Simondon, is needed here. According to Giorgio Agamben,

Where classical science saw a unique world that contained all living species, ranked by hierarchy, from the most basic forms to complex superior organisms, Uexküll imagines instead an infinite variety of perceptive worlds, each equally perfect and connected to the others as if they laid on a gigantic music score, despite being non-communicative and mutually exclusive, and which hold in their center small beings both familiar and distant. ${ }^{29}$

Uexküll often employed music as a metaphor. The musical model from which the German thinker drew inspiration is pre-eminently a classical one, yet we will use his ethology-based concept of milieu to understand today's musical evolutions.

In an effort to name these multiple worlds that correspond to each animal species, Uexküll coins the concept of Umwelt, 'world-around', which can be translated as 'milieu'. Each living species possesses its own Umwelt and gives it meaning, and it in turn imposes its attributes on the species. The Umwelt makes up just a small part of the environment, or Umgebung, and comprises only the objects that the animal interacts with. These interactions are based upon the perception-action loop and produced by the physiological senses, which inject a sense of subjectivity, albeit one that is species-centric.

There is the famous case of the tick: "All the richness of the world (that surrounds it) hardens and transforms into a poor product, composed of only three perceptive signs and three agent signs. These are its milieus. ${ }^{30}$ Uexküll devotes little attention to human milieus, but in an effort to back up his hypothesis of parallel worlds, concludes his book by writing that 'the milieus of an aerial wave specialist and of a musicologist attest to the same difference. There are only waves in one, only sounds in the other. But each is no less real than the other. ${ }^{31}$

This example allows us to clarify the notion of 'sound milieus'. 'Milieu' was the focus of this debate on the notion of sound from the very beginning: it is the space where vibrations triggered by a moving object spread and create sound. (This milieu is predominantly aerial, but it may also be liquid or solid.) Yet Uexküll's text compels 


\section{Paragraph}

us to abandon the physicalist perspective that defines these milieus as objective spaces and instead consider them as the milieus of something. These milieus are not air, liquid nor solid in their entirety; they merely make up an individual part that is defined by the subject that interacts with it.

If we take the listener as our subject, then it is understood that, through the act of listening, he interacts with a sound milieu, resulting in what we call sound. Sound is therefore not an object, neither the vibrating object nor the space in which the vibrations take place; sound is rather the product of the interaction between the listener and the milieu. Listening is no longer about contemplating the objects before us, but about being immersed in a milieu. Additionally, because a milieu is just a part of the environment, the act of listening is not a truncated perception focused on one sense and which anaesthetizes the other senses: it weaves the relationship between the subject and a particular milieu, the sonic milieu, which coexists with the visual, tactile and other milieus.

We shall now turn to Gilbert Simondon's interpretation of the notion of milieu, which will enable us to clarify the relationship between sound and the sound milieu. Simondon uses the concept of milieu in both its meanings: 'milieu', or environment, and 'milieu', literally the middle of a place, or centre. To give meaning to the extremes, and distinguish the individual from the milieu (as opposed to the subject and object opposition, or the spirit and the world opposition), we must begin with mi-lieu as centre i.e. with relationality as such. "To be sure, beginning with the mi-lieu implies beginning neither with the individual, nor with the milieu! Indeed, the milieu could not exist as such prior to individuation.' ${ }^{32}$

Passing on to sound milieus, simply transposing some of Simondon's concepts in two of his sentences will help to further our understanding of sound as 'individuation'. According to Simondon, 'We must start from individuation, from being determined at its centre by spatiality and becoming, and not from an individual substantialized before a foreign world. 33 If we replace 'individuation' with 'becoming-sound', 'being' with 'sound space' and 'individual' with 'sound' in the original text, we get: 'We must start from becoming-sound, from the sound space determined at its centre by spatiality and becoming, and not from a sound substantialized before a foreign world.' The second original sentence reads: 'Individual and milieu must be understood only as the extreme terms, conceptualizable but not substantializable, of being in which individuation operates. ${ }^{34}$ With the same substitutions, it would 
become: 'Sound and sound milieu must be understood only as the extreme terms, conceptualizable but not substantializable, of the sound space in which becoming-sound operates.' I would add that Simondon is also valuable on account of his notion of a 'technical milieu', which is the crowning element of his argument, because sound milieus are largely created by technology. The transposition can be summarized in three statements. (1) An undistinguished whole exists, and this is the sound space. (2) Sound appears by way of a becoming; its complement is the sound milieu. (There are therefore two entities, sound and the often technical sound milieu, but sound is never an object. It is always defined by its relationship to the milieu; inversely, the sound milieu is not a simple environment.) (3) The way in which sound 'appears' - or, in other words, the equivalent of individuation, according to Simondon - constitutes an emergence.

To conclude this analysis of expressions that pass beyond the concept of sound in favour of a relational approach, we will now turn to ambiance, a concept that has been frequently applied to the interdisciplinary field of urban spaces. Developed in France by the Grenoble-based laboratory CRESSON, the concept was further globalized through the Ambiances network and the journal Ambiances. Though it originally focused on sonic ambiances, research has since extended to light, thermal, olfactory, tactile and kinaesthetic phenomena. The specificity of this concept, as opposed to more general concepts of space and environment, lies in its sensory dimension. Jean-François Augoyard, referring to architecture, wrote that 'from ambiances to ambiance, the challenge is to raise awareness of the architect's intuitive production of sensory qualities in the project'. ${ }^{35}$ With regards to the domain of art, this concept aims to introduce sensory perception itself to the notion of aesthetics. As JeanPaul Thibaud wrote, 'the concept of ambiance affects the aesthetic primarily because it questions human sensoriality. (...) It allows us to return to the principal meaning of aesthetics, which is the theory of sensitive perception. ${ }^{36}$

The concept of atmosphere - which is, in a way, the source of the concept of ambiance - was developed by the German philosopher Gernot Böhme, who initially introduced it in his book Für eine ökologische Naturästhetik (1989) as a means to establish a link between the human factor and environmental science. "What affects human beings in the environment are not only just natural factors but also aesthetic ones,' he wrote, adding that 'what mediates objective factors of the environment with aesthetic feelings of a human being is 
what we call atmosphere. ${ }^{37}$ In art, this concept has a tendency to privilege experience over knowledge. In classical aesthetics, as put forward by Kant and Hegel, art is made for elites who must be educated by providing them with knowledge through words and images. The amateur does not experience a work of art directly and is mainly concerned with its meaning. With the concept of atmosphere, however, it is experience that is privileged. This conceptual turning point in aesthetics intersects the shift towards the experiential element of art and manifests itself in land art and other ephemeral, site-specific installations. As a result, 'in order to adequately appreciate what these works of art are requires exposing oneself to the atmosphere they are radiating, 38

Böhme has also studied new music and describes its accent on sound and space as particularly atmospheric. ${ }^{39}$ At the same time, contextualizing music within the aesthetics of atmosphere allows one to redefine the emotional effect of music:

The discovery that music is the fundamental atmospheric art has solved an old, always annoying and yet inescapable problem of musical theory, i.e. the question: of what does music's so-called emotional effect actually consist? In opposition to the helpless association theories and the theories that called upon fantasy to mediate, the Aesthetics of Atmospheres gives a simple answer to the question: music as such is a modification of space as it is experienced by the body. Music forms and informs the listener's sense of self (das Sichbefinden) in a space; it reaches directly into his or her corporeal economy. ${ }^{40}$

\section{Conclusion: Sound Fetishism}

Sound inhabits man's life today in a way it never has before: it is as though the vast space in which we live has been turned into a sound system, setting off a hypertrophy of our sound environment. Music in particular has been transformed into an immense sonic flood: for some, it is a devastating planetary tsunami, and for others it is a universal, nourishing amniotic fluid. With the advent of sound recording and other technological advances, listening to music no matter where we are is not only possible but inevitable. Globalization has further enabled us to listen to anything we want - or don't want. We are living in a world of ubiquitous music and sound that demands nonstop listening.

This situation has inevitably prompted certain alienating behaviours. Hildegard Westerkamp, the pioneer of acoustic ecology, has described this need to have sound and music at all times: 
[It] resembles the desire for womblike comfort. The difference is that this 'womb' is artificially created and therefore disconnected from the real world, whereas the real womb is intricately connected with it. To seek out an artificially created 'womb' is like suffering from aural addiction. It is a psychological addiction that puts a screen of illusion between us and the world as well as, and perhaps more seriously, between us and our imagination, between us and our emotions, between us and our thoughts. In this womb all knowledge of how to listen or how to make sound has left us. What we hear is a homogeneous music. ${ }^{41}$

More and more musicians and sound artists, as well as sound and music theorists, have begun to push back against this new form of alienation, or sound fetishism. They defend the hypothesis put forward in this article: that sound cannot be taken as an object, but must be considered as a fabric of relationships that includes not only the imagination and the listener's body, but the (real) environment as well.

Translated by Jenny Che

\section{NOTES}

1 Pierre Schaeffer, A la recherche d'une musique concrète (Paris: Seuil, 1952), 41-2.

2 Pierre Schaeffer, Traité des objets musicaux (Paris: Seuil, 1966), 268.

3 Schaeffer, 'Morphologie et typologie des objets sonores' in Traité des objets musicaux, 389-474.

4 Michel Chion, Le Son (Paris: Nathan/HER, 2000), 46.

5 Roberto Casati and Jérôme Dokic, La Philosophie du son (Nimes: Chambon, 1994), 7.

6 Agostino Di Scipio, 'Objet sonore? Evénement sonore! Idéologies du son et biopolitique de la musique' in Musique et écologies du son. Propositions théoriques pour une écoute du monde / Music and Ecologies of Sound: Theoretical Projects for a Listening of the World, edited by Makis Solomos, Roberto Barbanti, Guillaume Loizillon, Kostas Paparrigopoulos and Carmen Pardo (Paris: L'Harmattan, 2016), 35-46 (37-40).

7 Philippe Leroux, '...phraser le monde : continuité, geste et énergie dans l'œuvre musicale', Circuit 21.2 (2011), 29-48 (29).

8 See François Bayle, Musique acousmatique. Propositions ... positions (Paris: Buchet/Chastel, 1993), 142.

9 Gérard Grisey, Ecrits ou l'invention de la musique spectrale, edited by Guy Lelong with Anne-Marie Réby (Paris: Musica falsa, 2008), 120.

10 On modern music and energy, see Christophe Cassagrande, L'Energétique musicale (Paris: L'Harmattan 2009). 
11 See Makis Solomos, 'Xenakis ou la musique comme énergie', in Musica. Festival des musiques d'aujourd'hui, festival programme (Strasbourg, 2011), 36-8.

12 Consulted in the Iannis Xenakis archives, carnet 23.

13 Iannis Xenakis, 'Elements of Stochastic Music', Gravesaner Blätter 18 (1960), 84-105, reprinted in Iannis Xenakis, Musiques formelles = Revue musicale 253-4 (1963), chapter 2.

14 Horacio Vaggione, 'Composition musicale et moyens informatiques: questions d'approche' in Formel/Informel: musique-philosophie, edited by Makis Solomos, Antonia Soulez and Horacio Vaggione (Paris: L'Harmattan, 2003), 91-116 (102).

15 See Makis Solomos, De la musique au son. L'Emergence du son dans la musique des XXe-XXIème siècles (Rennes: Presses universitaires de Rennes, 2013).

16 Giacinto Scelsi, Les Anges sont ailleurs. . . , unpublished works collected, edited and commented by Sharon Kanach (Arles: Actes Sud, 2006), 126.

17 Roberto Barbanti, 'Ecologie sonore et technologies du son', Sonorités 6 (2011), 11-42 (13).

18 See Tim Ingold, The Perception of Environment. Essays on Livelihood, Dwelling and Skill (London: Routledge, 2000).

19 See Solomos, De la musique au son, chapter 6, 415-90.

20 See the volumes Soundspaces. Espaces, expériences et politiques du sonore, edited by Claire Guiu, Guillaume Faburel, Marie-Madeleine Mervant-Roux, Henry Torgue and Philippe Woloszyn (Rennes: Presses universitaires de Rennes, 2014); and Music, Sound and Space: Transformations of Public and Private Experience, edited by Giorgina Born (Cambridge: Cambridge University Press, 2015).

21 R. Murray Schafer, The Tuning of the World. A Pioneering Exploration into the Past History and Present State of the Most Neglected Aspect of our Environment: The Soundscape (London: Random House, 1977). Quoted here from a digital version (Kindle) with no pagination.

22 Barry Truax, Handbook for Acoustic Ecology, The World Soundscape Project (Simon Fraser University, and ARC Publications,1978); republished 1999 by Cambridge Street Publishing and read online at: https:// www.sfu.ca/sonicstudio/handbook/, consulted January 2017.

23 R. Murray Schafer, 'Soundscape Studies: The Early Days and the Future', Soundscape: The Journal of Acoustic Ecology 12:1 (2012-13), 6-8 (6).

24 Schafer, The Tuning of the World, np.

25 Schafer, The Tuning of the World, np.

26 Schafer, The Tuning of the World, np.

27 Tim Ingold, 'Against Soundscape', in Autumn Leaves: Sound and the Environment in Artistic Practice, edited by Angus Carlyle (Paris: Double Entendre, 2007), 10-13. 
28 See A l'écoute de l'environnement. Répertoire des effets sonores, edited by Jean-François Augoyard and Henry Torgue (Marseille: Parenthèses, 1995); Frédéric Roulier, 'Pour une géographie des milieux sonores', Cybergeo: European Journal of Geography [e-journal], issue on 'Environnement, Nature, Paysage', document 71, posted online 21 January 1999, http://cybergeo. revues.org/5034, consulted 1 February 2017; Milieux Sonores/Klangliche Milieus. Klang, Raum und Virtualität, edited by Marcus Maeder (Bielefeld: Transcript, 2010); Christine Guillebaud, 'Towards an Anthropology of Sound Milieux. Perspectives from India', in Ambiances in action / Ambiances en actes, edited by Jean-Pierre Thibaud and Daniel Siret (Montreal: Réseau International Ambiances, 2012), 317-22.

29 Giorgio Agamben L'Ouvert. De l'homme et de l'animal, translated by Joël Gayraud (Paris: Rivages, 2006), 66.

30 Jakob von Uexküll, Milieu animal et milieu humain, translated and annotated by Charles Martin-Fréville (Paris: Rivages, 2010), 43. The German original, Streifzüge durch die Umwelten von Tieren und Menschen, appeared in 1934.

31 Uexküll, Milieu animal et milieu humain, 166.

32 Victor Petit, 'Le Concept de milieu en amont et en aval de Simondon', Cahiers Simondon 5 (2013), 45-58 (49).

33 Gilbert Simondon, L'Individuation à la lumière des notions de forme et d'information (Paris: Jérôme Million, 2005), 30.

34 Simondon, L'Individuation, 325.

35 Jean-François Augoyard, 'A comme Ambiance(s)', Les Cahiers de la recherche architecturale et urbaine 20/21 (2007), 33-7 (35).

36 Jean-Paul Thibaud, 'Petite archéologie de la notion d'ambiance', Communications 90:1 (2012), 155-74 (166).

37 Gernot Böhme, The Aesthetics of Atmospheres, edited by Jean-Paul Thibaud (London: Routledge, 2017), 2.

38 Böhme, The Aesthetics of Atmospheres, 6.

39 Böhme, The Aesthetics of Atmospheres, 165-75.

40 Böhme, The Aesthetics of Atmospheres, 171.

41 Hildegard Westerkamp, 'Listening and Soundmaking: A Study of Music-asEnvironment', MA thesis, Simon Fraser University, 1998, 33. 


\section{Your short guide to the EUP Journals Blog http://euppublishingblog.com/}

A forum for discussions relating to Edinburgh University Press Journals

\section{The primary goal of the EUP Journals Blog}

To aid discovery of authors, articles, research, multimedia and reviews published in Journals, and as a consequence contribute to increasing traffic, usage and citations of journal content.

\section{Audience}

Blog posts are written for an educated, popular and academic audience within EUP Journals' publishing fields.

\section{Content criteria - your ideas for posts}

We prioritize posts that will feature highly in search rankings, that are shareable and that will drive readers to your article on the EUP site.

\section{Word count, style, and formatting}

- Flexible length, however typical posts range 70-600 words.

- Related images and media files are encouraged.

- No heavy restrictions to the style or format of the post, but it should best reflect the content and topic discussed.

\section{Linking policy}

- $\quad$ Links to external blogs and websites that are related to the author, subject matter and to EUP publishing fields are encouraged, e.g.to related blog posts

\section{Submit your post}

Submit to ruth.allison@eup.ed.ac.uk

If you'd like to be a regular contributor, then we can set you up as an author so you can create, edit, publish, and delete your own posts, as well as upload files and images.

\section{Republishing/repurposing}

Posts may be re-used and re-purposed on other websites and blogs, but a minimum 2 week waiting period is suggested, and an acknowledgement and link to the original post on the EUP blog is requested.

\section{Items to accompany post}

- A short biography (ideally 25 words or less, but up to 40 words)

- A photo/headshot image of the author(s) if possible.

- Any relevant, thematic images or accompanying media (podcasts, video, graphics and photographs), provided copyright and permission to republish has been obtained.

- Files should be high resolution and a maximum of $1 \mathrm{~GB}$

- Permitted file types: jpg, jpeg, png, gif, pdf, doc, ppt, odt, pptx, docx, pps, ppsx, xls, xlsx, key, mp3, m4a, wav, ogg, zip, ogv, mp4, m4v, mov, wmv, avi, mpg, 3gp, $3 g 2$. 